\title{
Direction of glycan chain elongation by peptidoglycan glycosyltransferases
}

\author{
Deborah L. Perlstein, ${ }^{\dagger}$ Yi Zhang ${ }^{\ddagger}{ }^{\text {Tsung-Shing Wang, }}{ }^{\ddagger}$ Daniel E. Kahne ${ }^{*, *}$ \\ and Suzanne Walker ${ }^{*}$. \\ Department of Microbiology and Molecular Genetics, Harvard Medical School, \\ Boston, Massachusetts 02115 \\ and \\ Department of Chemistry and Chemical Biology, Harvard University, Cambridge, \\ Massachusetts 02138 \\ kahne@chemistry.harvard.edu; suzanne_walker@hms.harvard.edu
}

\section{Supporting information}


Materials: Bovine milk galactosyltransferase (GalT) was purchased from Sigma-Aldrich. UDP$\left[\mathrm{U}-{ }^{14} \mathrm{C}\right]$-galactose $(308 \mathrm{mCi} / \mathrm{mmol})$ was obtained from Amersham. C18 SPE columns were obtained from Alltech. Lipid II and Lipid IV were synthesized as described previously. ${ }^{1,2}$ E. coli PBP1A (amino acids 26-850 with C-terminal His-tag), ${ }^{3}$ E. coli $\mathrm{PBP} 1 \mathrm{~B},{ }^{4}$ A. aeolicus $\mathrm{PBP} 1 \mathrm{~A}$ (thioredoxin fusion to the PGT domain consisting of amino acids $29-243$ ), ${ }^{5}$ and S. aureus PBP2, ${ }^{6}$ were purified as described previously. Moenomycin A was isolated from flavomycin feedstock as described. ${ }^{7}$ All other chemicals were obtained from Sigma-Aldrich.

Synthesis of oligomer mix: PBP1A from E. coli $(0.5 \mu \mathrm{M})$ was incubated with $10 \mu \mathrm{M}$ Lipid IV in $50 \mathrm{mM}$ Hepes (4-(2-Hydroxyethyl)piperazine-1-ethanesulfonic acid, $\mathrm{pH} 7.5), 10 \mathrm{mM} \mathrm{CaCl}_{2}$, 20\% DMSO, $1 \mathrm{kU} / \mathrm{mL}$ Penicillin G (Buffer A). Reactions $(75 \mu \mathrm{L})$ were incubated at room temperature for $30 \mathrm{~min}$ and terminated by boiling.

LC/MS analysis of Lipid IV polymerization reaction: Lipid IV polymerization reaction $(50 \mu \mathrm{L})$ was set up described above in synthesis of oligomer mix. Reaction was terminated by boiling (10 min) and centrifuged. Soluble supernatant was dried by vacuum centrifugation and resuspended in $30 \mu \mathrm{L}$ water. Mass spectrometry data was collected with an Agilent $6210 \mathrm{TOF}$ LC/MS. The oligomers were separated on a C18 column (50×4.6 mm, Gemini, Phenomenex). Column was eluted with 5\% B for 5 min, followed by a linear gradient to $60 \%$ B over 20 min (A = water, $0.1 \% \mathrm{NH}_{4} \mathrm{OH} ; \mathrm{B}=$ acetonitrile, $\left.0.1 \% \mathrm{NH}_{4} \mathrm{OH}\right)$. The retention time and observed masses for the Lipid IV polymerization products are listed in Table S1. 
Table S1. LC/MS data of Lipid IV polymerization reaction

\begin{tabular}{lllll}
\hline Oligomer size & Retention time (min) & Ion & Observed & Calculated \\
\hline Lipid XII & 15.95 & {$[\mathrm{M}-6 \mathrm{H}]^{-}$} & 1056.4824 & 1056.4851 \\
& & {$[\mathrm{M}-5 \mathrm{H}]^{-}$} & 1267.9721 & 1267.9835 \\
& & {$[\mathrm{M}-4 \mathrm{H}]^{-}$} & 1585.2300 & 1585.2312 \\
\hline Lipid VIII & 17.61 & {$[\mathrm{M}-5 \mathrm{H}]^{-}$} & 888.6122 & 888.6155 \\
& & {$[\mathrm{M}-4 \mathrm{H}]^{-}$} & 1111.0170 & 111.0163 \\
& & {$[\mathrm{M}-3 \mathrm{H}]^{-}$} & 1481.6902 & 1481.6910 \\
\hline Lipid VI & 18.78 & {$[\mathrm{M}-4 \mathrm{H}]^{-}$} & 873.9135 & 873.9091 \\
& & {$[\mathrm{M}-3 \mathrm{H}]^{-}$} & 1165.5477 & 1165.5481 \\
\hline Lipid IV & 20.29 & {$[\mathrm{M}-4 \mathrm{H}]^{-}$} & 636.8031 & 636.8019 \\
& & {$[\mathrm{M}-3 \mathrm{H}]^{-}$} & 849.4065 & 849.4052 \\
& & {$[\mathrm{M}-2 \mathrm{H}]^{-}$} & 1274.6126 & 1274.6117 \\
\hline
\end{tabular}

Galactosyltransferase labeling of PGT substrates: Lyophilized powder of GalT was reconstituted to a concentration of $25 \mathrm{U} / \mathrm{mL}$ in $25 \mathrm{mM}$ Hepes, $5 \mathrm{mM} \mathrm{MnCl} 250 \%$ glycerol and stored at $-20^{\circ} \mathrm{C}^{8}$ Labeling reactions typically contained $5 \mu \mathrm{M}$ PGT substrate, $17 \mu \mathrm{M}$ UDP-[U${ }^{14} \mathrm{C}$ ]-Galactose $(308 \mathrm{mCi} / \mathrm{mmol}), 2.5 \mathrm{U} / \mathrm{mL}$ GalT, $25 \mathrm{mM}$ Hepes $\mathrm{pH} 7.9,5 \mathrm{mM} \mathrm{MnCl} 2,5 \%$ DMSO. Following incubation at room temperature for $>4 \mathrm{~h}$, reactions were terminated by boiling. The Gal-labeled substrates were purified by reverse phase chromatography C18 column with $0.1 \%$ ammonium bicarbonate and methanol supplemented with $0.1 \% \mathrm{NH}_{4} \mathrm{OH}$ mobile phases. The desired products were eluted with $100 \%$ methanol and dried by vacuum centrifugation. Recovery was determined by liquid scintillation counting. 
PGT assays determine if Gal-Lipid II and Gal-Lipid IV are PGT substrates in the presence of Lipid II: For the paper chromatography assays, $\left[{ }^{14} \mathrm{C}\right]$ Gal-Lipid II $(2 \mu \mathrm{M})$ or $\left[{ }^{14} \mathrm{C}\right]$ Gal-Lipid IV $(2$ $\mu \mathrm{M})$ were incubated with A. aeolicus PBP1A $(1 \mu \mathrm{M})$ in the presence or absence of Lipid II (20 $\mu \mathrm{M}$ ) in Buffer A. Following incubation for $1.5 \mathrm{~h}$ at $55^{\circ} \mathrm{C}$, reaction mixtures were spotted on a $1 \mathrm{x}$
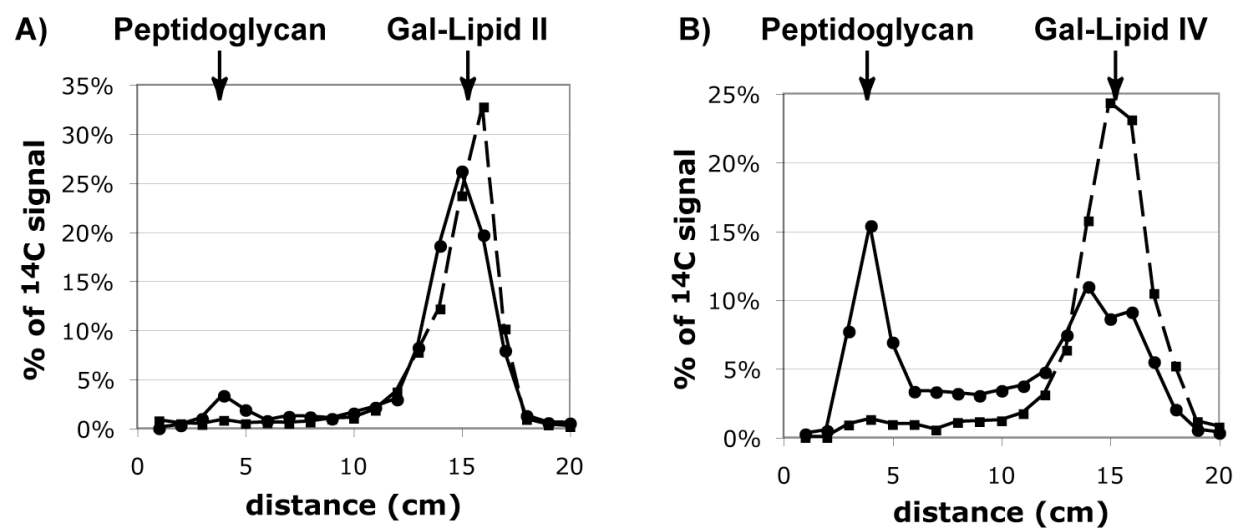

Figure S1. Incorporation of $\left[{ }^{14} \mathrm{C}\right]$ Gal-Lipid II and $\left[{ }^{14} \mathrm{C}\right]$ Gal-Lipid IV into peptidoglycan polymer. The PGT domain from A. aeolicus was incubated with either $\left[{ }^{14} \mathrm{C}\right] \mathrm{Gal}$-Lipid II $(\mathbf{A})$ or $\left[{ }^{14} \mathrm{C}\right]$ Gal-Lipid IV $(\mathbf{B})$ in the presence $(\bullet)$ or absence $(\boldsymbol{\square})$ of Lipid II. Products were analyzed by the PGT paper chromatography assay. The relative mobility of the peptidoglycan polymer product and the Gal-labeled substrate are indicated.

$20 \mathrm{~cm}$ strip of chromatography paper (3MM Whatmann) and developed with an ammonium hydroxide:isobutyric acid solution as described. ${ }^{1,9}$ The assays were analyzed by liquid scintillation counting (Figure S1).

For the gel electrophoresis assay (Figure S2), $\left[{ }^{14} \mathrm{C}\right]$ Gal-Lipid IV $(4 \mu \mathrm{M})$ was incubated with $E$. coli PBP1A $(0.8 \mu \mathrm{M})$ in the presence or absence of Lipid II or Lipid IV $(16 \mu \mathrm{M})$ in Buffer A. Following incubation at room temperature for $17 \mathrm{~min}$, the reaction was terminated by boiling, dried by vacuum centrifugation and analyzed by gel electrophoresis (method described below). The results are shown in Figure S2. No higher molecular weight band appears when the PGT is incubated with only the Gal-Lipid IV (compare Lanes 2 and 3; Figure S2); however, larger 
products do form when Lipid II (Lane 4) or Lipid IV (Lane 5) are included in the reaction. The major product formed from incubation of Gal-Lipid IV with Lipid IV is Gal-Lipid VIII. This assignment is supported by our mass spectrometry analysis of the Lipid IV polymerization reactions. The reaction of Gal-Lipid IV with Lipid II produces a ladder of products, which we have used to assign the oligomer size indicated to the right of the gel.

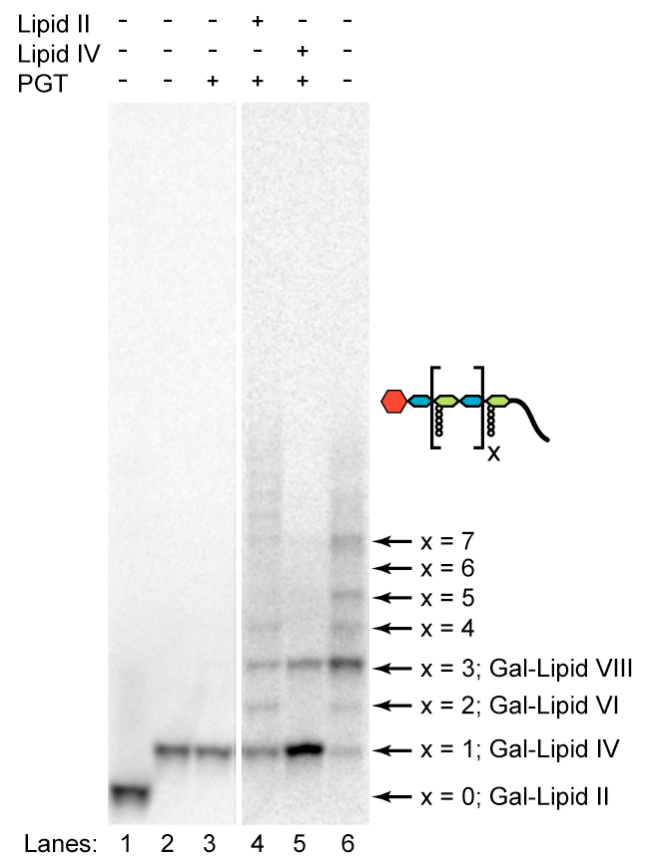

Figure S2. Gel electrophoresis analysis of PGT reactions with $\left[{ }^{14} \mathrm{C}\right]$ Gal-Lipid IV. $\left[{ }^{14} \mathrm{C}\right] \mathrm{Gal}-$ Lipid II and $\left[{ }^{14} \mathrm{C}\right]$ Gal-Lipid IV are shown in Lanes 1 and 2, respectively. Lanes 3-5 show reactions of $\left[{ }^{14} \mathrm{C}\right] \mathrm{Gal}-\mathrm{Lipid}$ IV with E. coli PBP1A in the presence or absence of Lipid II or Lipid IV, as indicated above each lane. Lane 6 is the Gal-labeled oligomer substrate. 
Figure S3. Scheme demonstrating that Gal-Lipid II can be incorporated into polymer by addition

A)

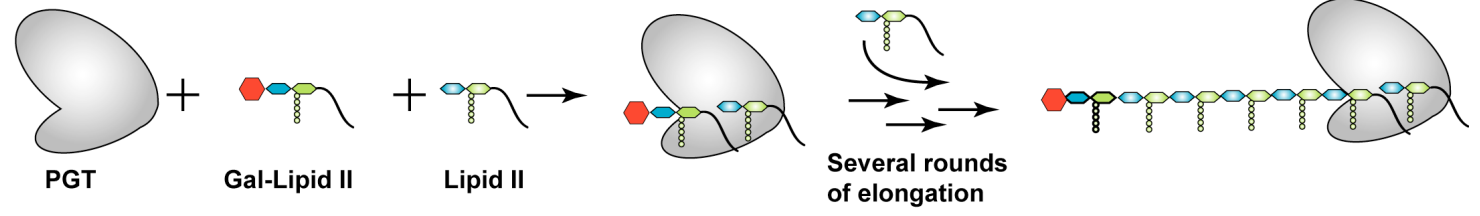

B)

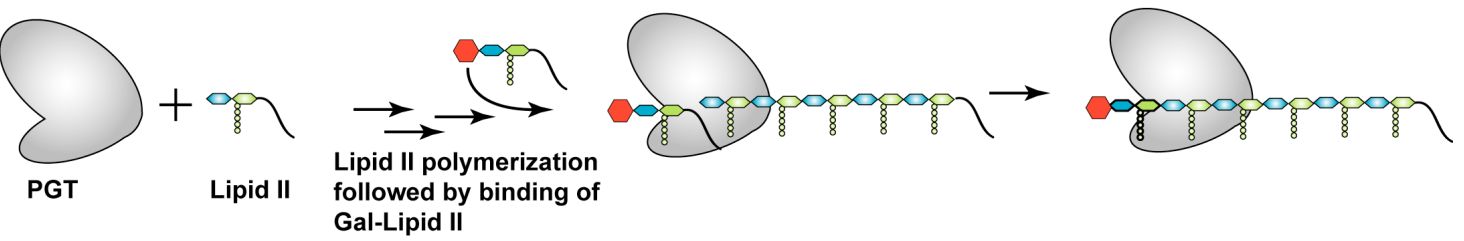

of new units to the reducing end (A) or by addition of new units to the non-reducing end (B).

Although both Gal-Lipid II and Gal-Lipid IV are substrates in the presence of Lipid II, we cannot use these analogs to determine the direction of elongation because Lipid II and Lipid IV can be self-condensed by PGTs. Figure S3 demonstrates that with either mechanism of elongation, we could generate co-polymers of Gal-Lipid II with Lipid II, and similar schemes can be drawn with Gal-Lipid IV. Therefore, we needed to generate longer polymers that cannot be self-condensed to determine the direction of glycan elongation.

PGT assays with Gal-labeled oligomers: Reactions $(5-10 \mu \mathrm{L})$ contained $\left[{ }^{14} \mathrm{C}\right]$ Gal-labeled substrate, PGT, and, when included, Lipid II as summarized in Table S2. Reactions for E. coli PBP1A and A. aeolicus PBP1A were carried out in Buffer A. Reactions with E. coli PBP1B were carried out in Buffer A supplemented with $2.3 \mathrm{mM}$ decyl-PEG. Reactions with $S$. aureus PBP2 were in $50 \mathrm{mM}$ CHES (2-[cyclohexylamino]ethanesulfonic acid), $50 \mathrm{mM}$ Hepes, $50 \mathrm{mM}$ acetic acid, $50 \mathrm{mM}$ MES (2-morpholineethanesulfonic acid), $10 \mathrm{mM} \mathrm{CaCl} 2,20 \%$ DMSO and 1 $\mathrm{kU} / \mathrm{mL}$ Penicillin $\mathrm{G}(\mathrm{pH} 4.5)$. All assays were carried out at room temperature, except for assays with A. aeolicus PBP1A, which were incubated at $55^{\circ} \mathrm{C}$. Reactions were quenched by the addition of $0.5 \mu \mathrm{L}$ of $100 \mu \mathrm{M}$ Moenomycin A. 
Table S2. Reaction conditions for the direction of elongation experiments.

\begin{tabular}{lllll}
\hline Enzyme & {$\left[{ }^{14} \mathrm{C}-\right.$ Gal-oligomer $]$} & {$[$ Lipid II] } & {$[\mathrm{PGT}]$} & Time (min) \\
\hline E. coli PBP1A & $3 \mu \mathrm{M}$ & $30 \mu \mathrm{M}$ & $0.5 \mu \mathrm{M}$ & $90 \mathrm{~min}$ \\
E. coli PBP1B & $3 \mu \mathrm{M}$ & $30 \mu \mathrm{M}$ & $0.25 \mu \mathrm{M}$ & $90 \mathrm{~min}$ \\
A. aeolicus $\mathrm{PBP} 1 \mathrm{~A}$ & $2.2 \mu \mathrm{M}$ & $22 \mu \mathrm{M}$ & $0.5 \mu \mathrm{M}$ & $50 \mathrm{~min}$ \\
S. aureus $\mathrm{PBP} 2$ & $2.2 \mu \mathrm{M}$ & $22 \mu \mathrm{M}$ & $2.9 \mu \mathrm{M}$ & $50 \mathrm{~min}$ \\
\hline
\end{tabular}

PGT gel electrophoresis assay: Gel electrophoresis was carried out as described previously. ${ }^{3}$ Briefly, samples were dried by vacuum centrifugation to less than $1 \mu \mathrm{L}$. Gel loading buffer (2-3 $\mu \mathrm{L})$ was added and the entire sample was loaded into a $5 \mathrm{~mm}$ lane in a $16 \times 20 \mathrm{~cm}$ gel $(1 \mathrm{~mm}$ thick, $10 \%$ acrylamide). Following migration of the dye front to within a few $\mathrm{mm}$ of the bottom of the gel, the gel was dried overnight and exposed to a tritium phosphorimage screen (GE Healthcare). Gel images were captured with a Typhoon phosphoimager (GE Healthcare) and data analyzed with the ImageQuant software package.

\section{References:}

1. Ye, X.; Lo, M.; Brunner, L.; Walker, D.; Kahne, D.; Walker, S., J. Am. Chem. Soc. 2001, $123,3155-3156$.

2. Zhang, Y.; Fechter, E. J.; Wang, T. S. A.; Barrett, D.; Walker, S.; Kahne, D. E., J. Am. Chem. Soc. 2007, 129, 3080-3081.

3. Barrett, D.; Wang, T. S. A.; Yuan, Y.; Zhang, Y.; Kahne, D.; Walker, S., J. Biol. Chem. 2007, accepted.

4. Barrett, D.; Chen, L.; Litterman, N.; Walker, S., Biochemistry 2004, 43, 12375-12381.

5. Yuan, Y. Q.; Barrett, D.; Zhang, Y.; Kahne, D.; Sliz, P.; Walker, S., Proc. Natl. Acad. Sci. U. S. A. 2007, 104, 5348-5353. 
6. Barrett, D.; Leimkuhler, C.; Chen, L.; Walker, D.; Kahne, D.; Walker, S., J. Bacteriol. 2005, 187, 2215-2217.

7. Adachi, M.; Zhang, Y.; Leimkuhler, C.; Sun, B.; LaTour, J. V.; Kahne, D. E., J. Am. Chem. Soc. 2006, 128, 14012-3.

8. Roquemore, E. P.; Chou, T. Y.; Hart, G. W., Methods Enzymol. 1994, 230, $443-60$.

9. Anderson, J. S.; Matsuhashi, M.; Haskin, M. A.; Strominger, J. L., Proc. Natl. Acad. Sci. U. S. A. 1965, 53, 881-889. 